\title{
Perancangan Sistem Informasi Warga Bintara Jaya berbasis Android dengan Waterfall Software Development Life Cycle
}

\author{
Putri Handayani $^{1)}$, Aji Setiawan ${ }^{2 *}$ \\ ${ }^{1,2}$ Jurusan Teknik Informatika, Fakultas Teknik, Universitas Darma Persada, Jakarta \\ ${ }^{1,2}$ J1. Raden Inten II, Kota Jakarta Timur, Kode Pos 13450, Jakarta, Indonesia \\ email: ${ }^{1}$ handayaniputri948@gmail.com ${ }^{2}$ aji_setiawan@ft.unsada.ac.id
}

Copyright @2019, Politeknik Harapan Bersama, Tegal

\begin{abstract}
Rukun Tetangga / Rukun Warga is an inseparable part of Indonesian citizens ranging from administrative needs to social service needs such as information for residents, selection of new RT and RW leaders. The high interest of citizens towards services involving the RT head and other administrators often collided with the activities and daily activities of the administrators, resulting in limited and obstructed services for residents. This study aims to find the concept of system models that are needed by citizens to create ease in the management of messages and communication between the right citizens so that the time constraints that occur can be reduced. The research begins with designing a problem-based analysis design with the waterfall method. The method consists of sequential processes beginning with the analysis phase, system design, coding, implementation and maintenance of the system. The stages of system analysis, business process modeling using the Unified Modeling Language approach are used by use case and activity diagrams. The results of the study concluded that the application of the waterfall method could have an impact on the system development process to be more systematic and measurable, the system built was in accordance with what was expected by the residents.
\end{abstract}

Abstrak - Rukun Tetangga/ Rukun Warga merupakan bagian yang tidak terpisahkan dari warga indonesia mulai dari keperluan administratif hingga keperluan layanan sosial seperti informasi bagi warga, pemilihan ketua RT dan RW baru. Tingginya kepentingan warga terhadap layanan yang melibatkan ketua RT maupun pengurus lainnya seringkali berbenturan dengan aktivitas dan kesibukan keseharian para pengurus sehingga berakibat terjadinya kendala pelayanan bagi warga menjadi terbatas dan terhambat. Penelitian ini bertujuan untuk menemukan konsep model sistem yang dibutuhkan warga untuk menciptakan kemudahan dalam pengelolaan pesan dan komunikasi antar warga yang tepat agar keterbatasan waktu yang terjadi bisa dikurangi. Penelitian diawali dengan merancang design analisis berdasarkan permasalahan dengan metode waterfall. Metode terdiri dari proses yang berurutan diawali tahap analisa, desain sistem, coding, implementasi dan pemeliharaan sistem. Tahapan analisa sistem, pemodelan proses bisnis menggunakan pendekatan Unified Modeling Language diantarnya use case dan activity diagram. Hasil penelitian menyimpulkan bahwa penerapan metode waterfall dapat berdampak pada proses pengembangan sistem menjadi lebih sistematis dan terukur, sistem yang dibangun telah sesuai dengan yang diharapkan warga.

*) penulis korespondensi: Aji Setiawan

Email: aji_setiawan@ft.unsada.ac.id
Kata Kunci - Sistem Informasi warga, Unified Modeling Language, Waterfall.

\section{PENDAHULUAN}

Sistem informasi dilingkungan warga sangat jarang diaplikasikan, padahal dengan adanya sistem informasi memiliki banyak dampak sosial dan ekonomi terdahap masyarakat modern [1]. Permasalahan yang ditemui terkait aktivitas kegiatan warga seputar ke RT/RWan salah satunya adalah kesulitan warga menemui ketua RT maupun ketua RW karena rutinitas dan kesibukan pekerjaan mereka. Akibatnya kebutuhan warga perihal keperluan administrasi kependudukan menjadi terhambat karena mereka baru bisa mengurus di sore atau malam hari, dan masalah yang muncul dari sisi pengurus RT/RW adanya rasa enggan warga untuk secara sukarela menjadi pengurus ketika dalam kegiatan pelaksanaan pemilihan ketua RT/RW banyak warga yang tidak bisa datang untuk memberikan suaranya, sehingga acara pemilihan ketua RT/RW tidak berjalan lancar dan hasil pemilihan ketua RT/RW tidak sesuai harapan.

Melihat hal itu, maka perancangan sistem aplikasi mobile berbasis android yang dapat memberikan berbagai informasi dan kemudahan [2] pada warga terkait dengan kegiatankegiatan yang akan diselenggarakan termasuk dalam hal kegiatan pemilihan RT maupun hal-hal lainnya yang bersangkutan dengan RT/RW setempat, dan memberikan layanan pengajuan surat atau layanan warga. Sistem dibangun berdasarkan metodologi pengembangan waterfall, metode ini sering digunakan karena memiliki kelebihan diantaranya memiliki struktur tahap pengembangan sistem yang sudah jelas, mewajibkan adanya dokumentasi disetiap tahap pengembangannya dan keterurutan proses dimana proses tidak akan berjalan maju sebelum proses sebelumnya dikatakan selesai [3]. Tujuan dari penelitian ini mencoba menemukan konsep model sistem yang sesuai dengan kebutuhan dan permasalahan dilapangan khususnya dalam hal kemudahan, kelancaran dalam berkomunikasi untuk kebutuhan pelayanan warga dan sebaliknya. Melalui sistem ini warga dapat melakukan kegiatan pemilihan RT melalui via smartphone tanpa harus datang ketempat untuk melakukan pemilihan, warga juga dapat mengajukan pengajuan surat pengantar, penyampaian aspirasi atau hanya sekedar melihat informasi dan fitur tambahan berupa panic button yang dapat 
digunakan dalam keadaan darurat. Dengan sistem ini juga nantinya para pengurus RT/RW bisa memberikan layanan administasi kepada warganya dan memberitahu informasi yang terkait lingkungan.

\section{PENELITIAN TERKAIT}

Penelitian yang berhubungan dengan perancangan sistem manajemen warga sudah pernah dilakukan oleh beberapa peneliti diantaranya S Raharjo dkk (2017) [4], dalam penelitiannya mengembangkan sebuah aplikasi mobile yang digunakan dikelurahan dengan keunggulan fitur pencatatan pengguna, media penyimpanan dan pengolahan data warga yang memberikan informasi pertumbuhan warga pada suatu lokasi. Kesimpulan yang didapatkan dari sistem yang dibuat dapat meningkatkan keakuratan, efektifitas dan efisiensi serta tingkat mobilitas dilokasi penelitian. Perbedaan objek penelitian yang kami lakukan dimana objek penelitian antara warga dengan ketua RT dan RW serta para pengurus.

Paryanta (2017), dalam penelitiannya mencoba memanfaatkan sistem informasi pedesaan berbasis web di desa sawahan untuk membantu aktifitas adminstrasi masyarakat. Pada penelitian ini metode yang digunakan adalah analisis PIECES (Performance, Information, Economy, control, Efficiency and Service), dan metode waterfall sebagai metodologi perancangan sistem, serta DFD (Data Flow Diagram) dalam menggambarkan arus data [5].

Karusala (2017), dalam seminar memaparkan beberapa faktor yang mempengaruhi persepsi terkait keselamatan bagi para wanita, hasil penelitian menemukan bahwa rasa aman harus diseraskan dengan beberapa faktor seperti keamanan bersifat private, publik, sosial dan terkait penggunaan teknologi [6].

Penelitian yang dilakukan Khambali, dkk (2017), dalam mengolah data cuaca melalui pendekatan metode waterfall hasil penelitian didapatkan bahwa proses tahapan pengembangan sistem yang dibuat menjadi lebih terstruktur pada setiap tahapannya [7] mempertegas landasan kami dalam menggunakan metode waterfall.

\section{A. Data Penelitian}

\section{METODE PENELITIAN}

Data primer yang didapat berdasarkan hasil wawancara terkait permasalahan yang dihadapi ketua RW dan RT dilokasi penelitian, data diambil dengan melakukan observasi. Setelah itu dilakukan studi pustaka untuk memperkuat literatur penelitian yang diharapkan hasil penelitian sesuai dengan yang diinginkan.

\section{B. Software yang digunakan}

Android studio versi 3.4 digunakan sebagai engine utama dalam membangun aplikasi android dan mysql sebagai basis data sebagai media penyimpanan data.

\section{Metode Pengembangan Perangkat Lunak}

Pada penelitian ini kami menggunakan metode penulisan yang bersifat deskriptif dimana dalam penulisan desktiptif hasil dari penelitian di tuliskan secara jelas dan mendeskripsikan inti dari penulisan dan untuk metode pengembangan perangkat lunak menggunakan metode SDLC Waterfall yang memiliki tahapan yang runtut [8]. Gambaran urutan metode waterfall bisa terlihat digambar 1.

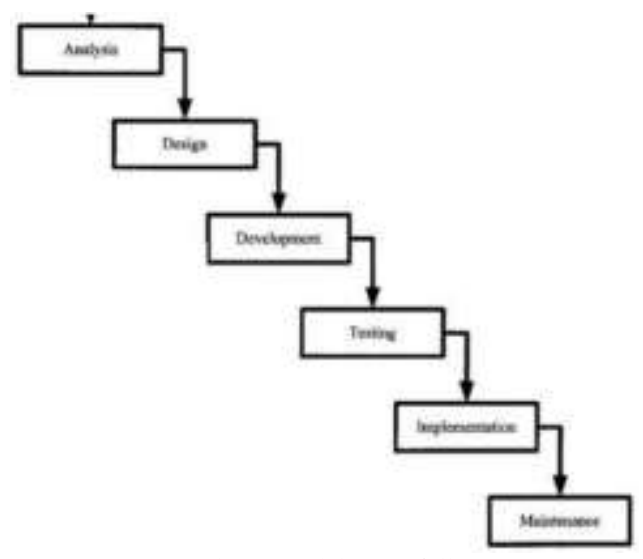

Gbr. 1 Model Waterfall

Langkah-langkah yang dilakukan untuk penelitian yang kami lakukan adalah sebagai berikut :

1) Analisa kebutuhan, melakukan identifikasi terkait kebutuhan apa saja yang diperlukan dalam pengembangan sistem berbasis mobile. Berdasarkan hasil obervasi lapangan, didapatkan data kebutuhan layanan warga dan mayoritas para warga telah mempunyai smartphone pribadi, kemudian hasil analisa tersebut mulai di gambarkan kebutuhan software dan hardware yang akan digunakan.

2) Perancangan, membuat konsep grand design yang bersifat sementara untuk menggambarkan pengembangan sistem. Pada proses ini diperlukan kebutuhan input dan output yang diharapkan.

3) Development, tahap dimana hasil dari perancangan yang dibuat diaplikasikan kedalam sebuah sistem dengan menggunakan bahasa pemrograman yang telah dirumuskan pada tahap analisa kebutuhan.

4) Pengujian, tahap melakukan percobaan aplikasi yang telah dibangun, pada tahap ini dievaluasi seluruh kebutuhan yang telah dijadikan sebuah sistem apakah sudah sesuai atau belum.

5) Implementasi, tahap dimana pembangunan aplikasi telah selesai dan penggunaan aplikasi sudah bisa diterapkan.

6) Maintenance, tahap melakukan pemeliharaan sistem yang sudah berjalan. Sehingga manfaat dan kebergunaan sistem bisa berlangsung lama.

\section{HASIL DAN PEMBAHASAN}

\section{A. Kebutuhan Sistem}

Pengembangan yang dilakukan berdasarkan perangkat android minimal OS Android 4.0 (ice cream sandwitch) dan RAM yang digunakan $512 \mathrm{mb}$.

\section{B. UML Diagram}

Pada design perencanaan, kami melakukan perencanaan dengan menggunakan UML seperti diagram use case, diagram activity, dan diagram class. Untuk use case dapat dilihat pada Gbr.2, Gbr.3 dan Gbr.4.

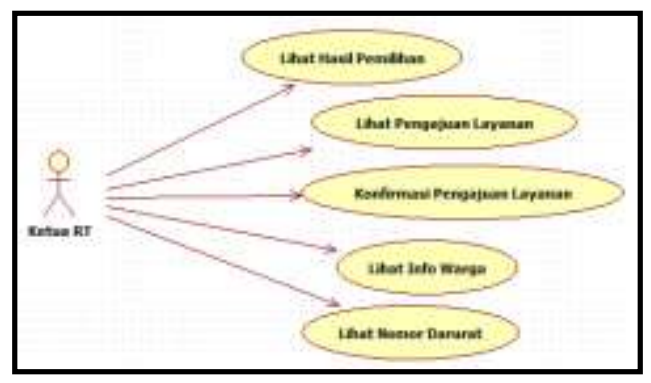




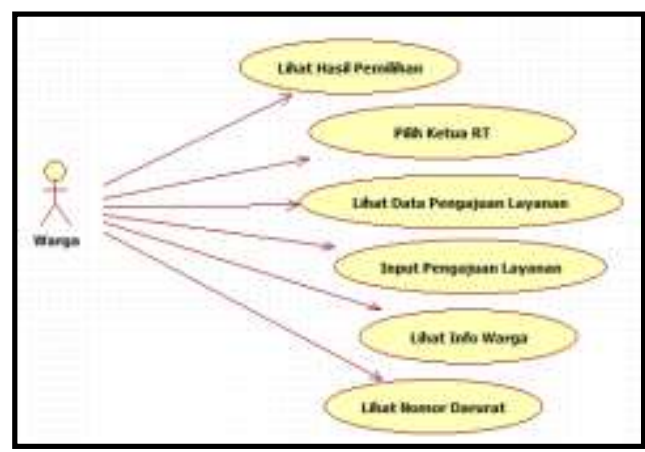

Gbr. 2 Use case model

Aktor Ketua RT dapat melihat hasil pemilihan, melihat pengajuan layanan yang tersedia serta mengkonfirmasi pengajuan layanan, dapat menginput info warga serta melihat info warga, dan melihat nomor darurat setelah melakukan login. Sedangkan aktor warga dapat melihat hasil pemilihan, melakukan pemilihan RT, menginput pengajuan layanan warga, dapat menginput info warga serta melihat info warga, dan melihat nomor darurat.

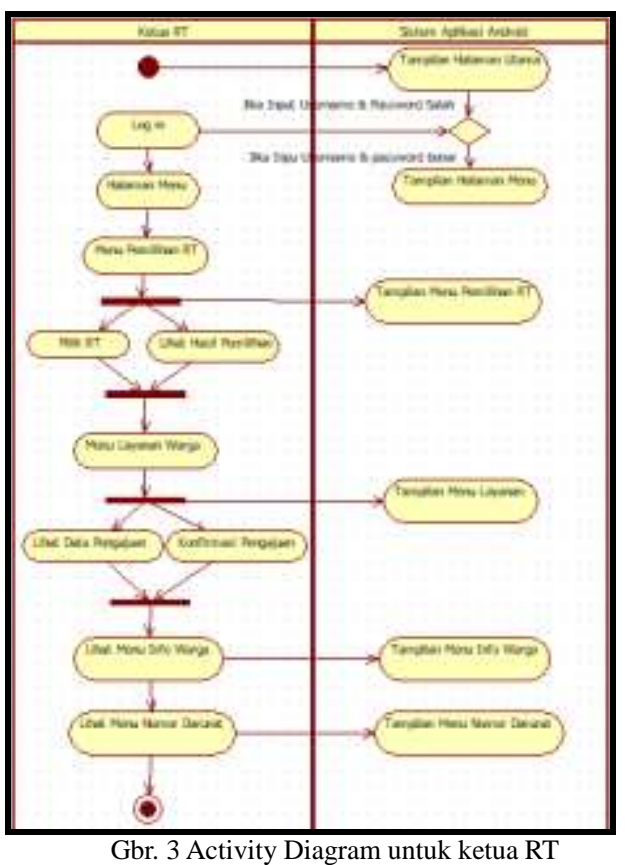

Ketua RT memiliki beberapa aktivitas yang dapat dilakukan di sistem. Langkah awal ketua RT perlu $\log$ in untuk bisa masuk ke dalam halaman menu android. Setelah itu, selanjutnya ketua RT dapat mengatur konfigurasi pemilihan RT dan melihat hasil pemilihan, dapat juga melihat data pengajuan layanan warga serta dapat mengkonfirmasi pengajuan layanan warga. Selain itu Ketua RT dapat melihat menu info warga dan menu nomor darurat.

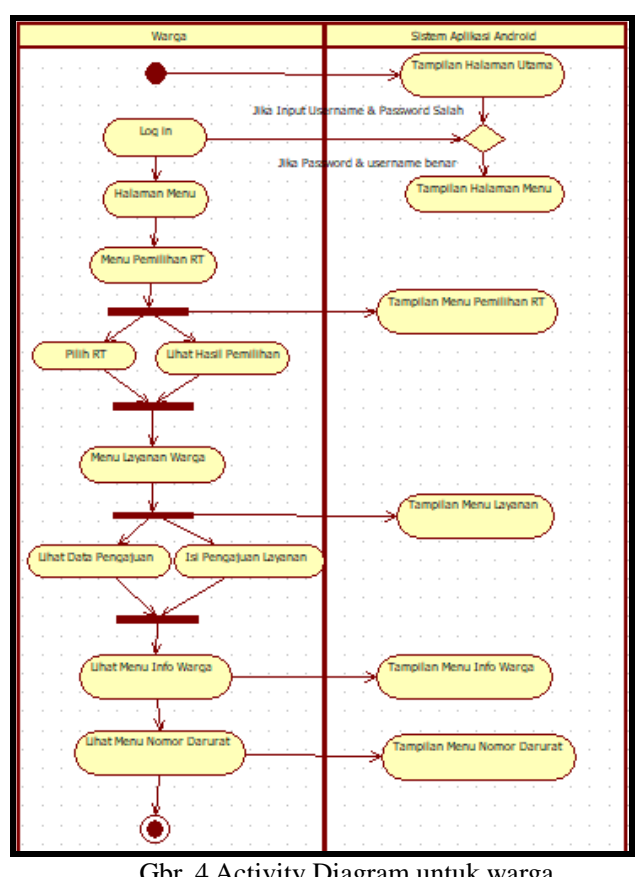

Gbr. 4 Activity Diagram untuk warga

Warga memiliki beberapa aktivitas yang dapat dilakukan dalam sistem, setiap warga memulai dengan log in agar bisa masuk ke dalam halaman menu android. Setelah itu, warga dapat melakukan pemilihan RT dan melihat hasil pemilihan, dapat melihat data pengajuan layanan warga serta dapat mengisi form pengajuan layan. Selain itu warga dapat melihat menu info warga dan menu nomor darurat.

Hasil penelitian berupa aplikasi berbasis mobile android dengan beberapa interface mobile sebagai frontend dan interface web untuk laman backend. Berikut adalah halaman web login backend yang digunakan untuk dapat melakukan pengaturan.

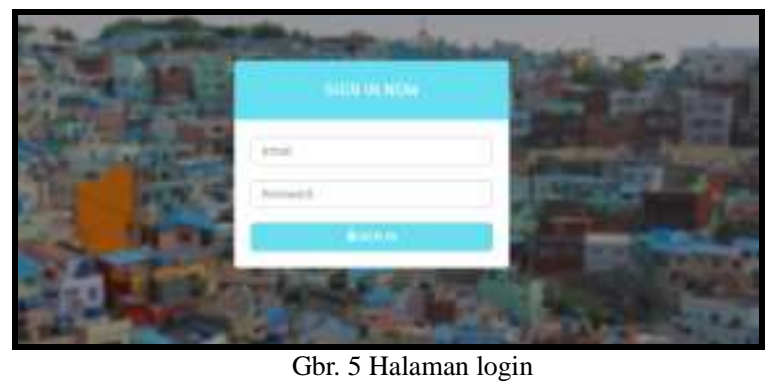

Halaman login website merupakan salah satu halaman backend yang digunakan sebagai langkah awal untuk memasuki halaman admin dalam aplikasi pemilihan ketua RT/RW di lingkungan warga bintara jaya. Jika username ataupun password yang diinput salah maka pengguna tidak dapat melakukan login, warga harus secara aktif menghubungi RT setempat untuk diusulkan pendaftaran akun nya. 


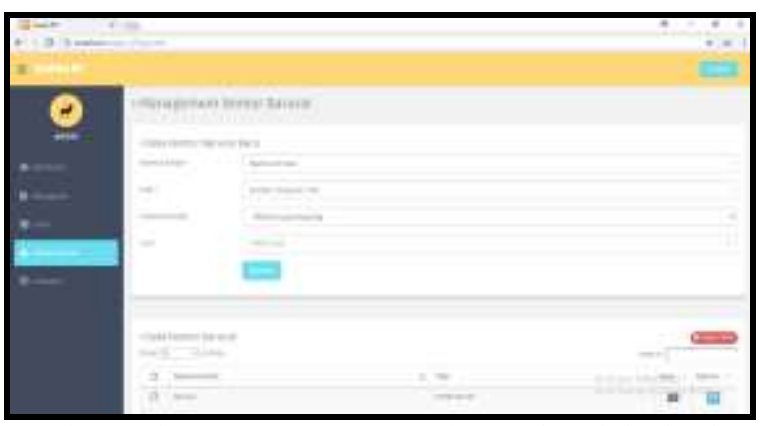

Gbr. 6 Halaman pengaturan nomor darurat via web backend

Halaman nomor darurat (panic button) ini adalah salah halaman untuk admin menambah data nomor darurat yang akan digunakan pada aplikasi pemilihan ketua RT/RW di lingkungan warga bintara jaya. Fitur ini merupakan salah satu hasil kebutuhan berdasarkan observasi yang telah dilakukan pada tahap analisa kebutuhan. Seluruh pengaturan sistem akan dilakukan melalui halaman web untuk memudahkan manajemen pendataan dan pengaturan sistem.

Untuk kebutuhan warga lebih banyak berinteraksi melalui laman apps android melalui smartphone yang mereka miliki. Penggunaan mobile juga sudah berdasarkan hasil observasi lapangan dimana para warga rata-rata sudah memiliki smartphone android minimal 1 kepala keluarga satu perangkat.
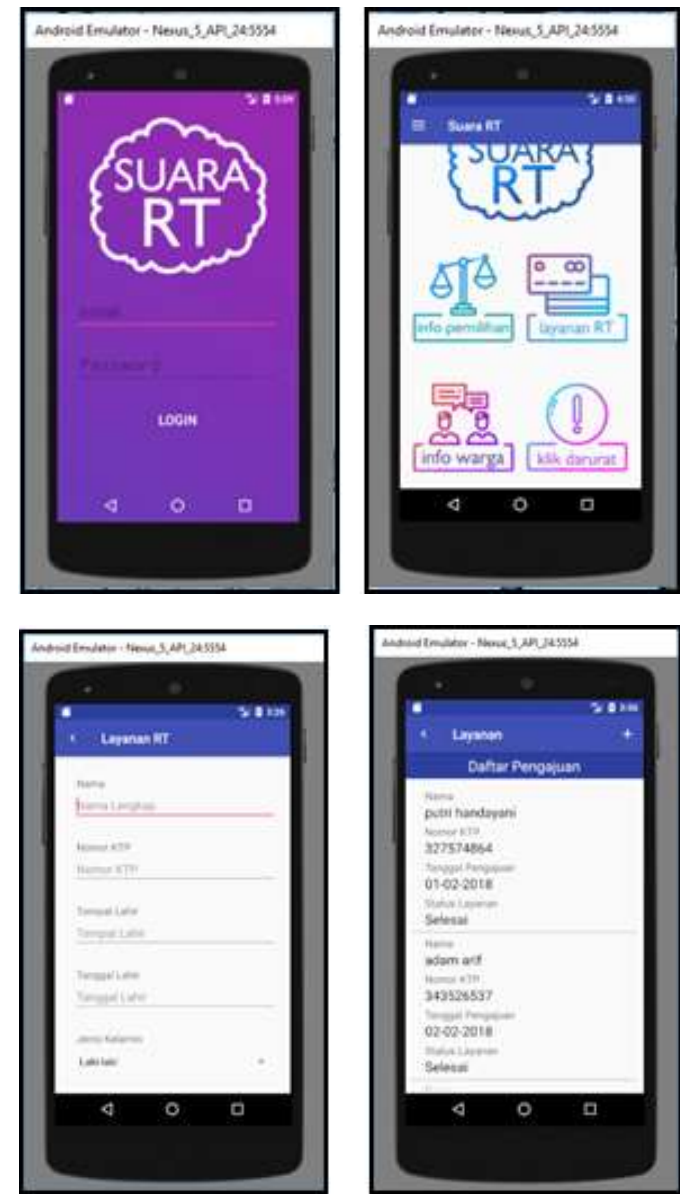

Gbr. 7 Halaman mobile untuk pengajuan layanan dan status warga

Di halaman ini warga dapat melihat daftar pengajuan layanan yang diminta serta melihat status dari pengajuan layanan tersebut dihalaman ini juga terdapat form pengajuan layanan yang bisa diakses dan diisi oleh para warga untuk meminta pengajuan layanan kepada Ketua RT. Kemudian terdapat fitur panggilan darurat apabila terjadi hal-hal yang tidak diinginkan menimpa salah satu warga, maka akan menghubungi nomor keamanan / satpam yang berjaga dilokasi perumahan bintara jaya.

Pengujian sistem dilakukan dengan cara menganalisis hasil wawancara mengenai aplikasi yang telah diuji coba kepada 5 orang responden. Pada wawancara ini ada tiga poin utama dalam penilaian, yaitu (1) fungsionalitas, yang menitik beratkan dari segi kinerja dan fungsi kegunaan dari aplikasi, (2) tampilan yang menitikberatkan kepada visualisasi aplikasi dalam bentuk mobile dan tampilan setiap halaman, (3) informatif, yang menitik beratkan ketersediaan konten-konten penyedia informasi yang tersedia. Hasil wawancara responden menyimpulkan bahwa secara fungsional program berjalan baik, tampilan menarik dan informatif sehingga sistem dapat dilanjutkan untuk digunakan.

TABEL I

HASIL WAWANCARA RESPONDEN

\begin{tabular}{|l|l|}
\hline \multicolumn{1}{|c|}{ Responden } & \multicolumn{1}{c|}{ Komentar } \\
\hline Ketua RT & Program berjalan dengan baik \\
\hline Warga & $\begin{array}{l}\text { Secara keseluruhan cukup baik, } \\
\text { Namun perbaiki lagi dari segi } \\
\text { informasinya }\end{array}$ \\
\hline Warga & $\begin{array}{l}\text { Program mudah dimengerti dan } \\
\text { lebih informatif dalam proses } \\
\text { pemesanan }\end{array}$ \\
\hline Warga & $\begin{array}{l}\text { Tampilan terlihat menarik dan } \\
\text { menampilkan semua informasi } \\
\text { yang dibuuhkan }\end{array}$ \\
\hline Warga
\end{tabular}

V.

KESIMPULAN

Berdasarkan hasil pengujian dan pembahasan sebelumnya, dapat ditarik kesimpulan bahwa (1) Pembuatan perancangan aplikasi forum diskusi antar warga di lingkungan RT/RW berbasis android ini telah selesai dibangun dengan menggunakan metode waterfall yang mengikuti tahap setiap prosesnya. (2) Aplikasi pemilihan ketua RT/RW di lingkungan warga bintara jaya ini dirancang dan dibuat dalam bentuk mobile (android), untuk memudahkan warga dalam melakukan pemilihan Ketua RT melalui via smartphone karena sebelumnya pemilihan masih dilakukan dengan warga mendatangi ke tempat untuk melakukan pemilihan. (3) Setelah pengguna melakukan pengujian sistem dan kami wawancara didapatkan kesimpulan bahwa sistem dirasakan sudah baik.

Berdasarkan kesimpulan diatas, kami mengajukan beberapa saran agar bisa dijadikan pedoman untuk penelitian lebih lanjut diantaranya (1) penambahan fitur-fitur yang ada pada perancangan aplikasi pemilihan ketua RT/RW di lingkungan warga bintara jaya berbasis android dapat diperbanyak. (2) Pengujian faktor penerimaan pengguna denganpendekatan TAM [9], data modelling dengan SEM [10] dan metode perancangan menggunakan agile software development [11] diharapkan dilakukan pada penelitian berikutnya. (3) Diharapkan dimasa yang akan datang proses pemilihan bisa lebih ditingkatkan dalam hal keamanan 
dengan penggunaan teknologi IoT [12] sebagai bagian dari verifikasi pemilih, penggunaan enkripsi dan sebagainya.

\section{DAFTAR PUSTAKA}

[1] S. Deb, "Information Technology, Its Impact on Society and Its Future," Adv. Comput., vol. 4, no. 1, pp. 25-29, 2014.

[2] A. Setiawan, "Pengaruh Penerapan Remote Electronic Voting System (REVS) Terhadap Tingkat Partisipasi Pemilih Menggunakan Model UTAUT," J. Teknol. Terap., 2017.

[3] M. S. Rosa A.S, "Model Waterfall," 2016. 2016

[4] S. M. Raharjo, O. D. Nurhayati, and K. T. Martono, "Sistem Informasi Pencatatan Data Warga Kelurahan Berbasis Mobile," J. Teknol. dan Sist. Komput., 2017.

[5] Paryanta, Sutariyani, and D. Susilowati, "Sistem Informasi Administrasi Kependudukan Berbasis Web Desa Sawahan," IJSE Indones. J. Softw. Eng., 2017.

[6] N. Karusala and N. Kumar, "Women' s Safety in Public Spaces: Examining the Efficacy of Panic Buttons in New Delhi," in Proceedings of the 2017 CHI Conference on Human Factors in
Computing Systems - CHI '17, 2017.

[7] M. Khambali, S. Rohayah, and O. Somantri, "Pembangunan Aplikasi Pengolahan Data Unsur Cuaca Pada Stasiun Meteorologi Kota Tegal Berbasis Model Waterfall," J. Inform. J. Pengemb. IT, 2017.

[8] S. Balaji, "Waterfall vs v-model vs agile: A comparative study on SDLC," WATEERFALL Vs V-MODEL Vs Agil. A Comp. STUDY SDLC, vol. 2, no. 1, pp. 26-30, 2012.

[9] W. A. A. Al-Khowaiter, Y. K. Dwivedi, and M. D. Williams, "Examining the Role of Social Influence, Usefulness and Ease of Use for Determining the Mandatory Use of a Human Resource Information System in the Context of Saudi Ministries," Int. J. Electron. Gov. Res., 2015.

[10] F. D. Andriani, T. A. Napitupulu, and S. Haryaningsih, "The user acceptance factors of e-filing system in Pontianak," J. Theor. Appl. Inf. Technol., 2017.

[11] K. Kautz, "Investigating the design process: Participatory design in agile software development," Inf. Technol. People, 2011.

[12] J. E. Siegel, S. Kumar, and S. E. Sarma, "The future internet of things: Secure, efficient, and model-based," IEEE Internet Things J., 2018. 